\title{
FUNDAMENTOS DA TRANSIÇÃO AGROECOLÓGICA: RACIONALIDADE ECOLÓGICA E CAMPESINATO
}

\section{FOUNDATIONS OF AGROECOLOGICAL TRANSITION: ECOLOGICAL RATIONALITY AND PEASANTRY}

FUNDAMENTOS DE LA TRANSICIÓN AGROECOLÓGICA: LA RACIONALIDAD ECOLÓGICA Y DE LOS CAMPESINOS

\author{
Paula Camargo ${ }^{1}$ \\ paulaforni@yahoo.com.br
}

\begin{abstract}
Resumo: Diferentemente daquelas proposições de "agricultura alternativa", cujos anseios limitam-se a idealizar que a reprodução ampliada do capital possa ocorrer sem provocar efeitos devastadores, ambientais ou sociais, na perspectiva da agroecologia considerada por ALTIERI (2002), GUZMÁN; MOLINA (2005) e GUTERRES (2006) está posto que o posicionamento político-ideológico é necessário. Neste caso, partese da crítica às bases estruturantes do sistema de produção, concebendo o cotidiano da vivência camponesesa como renovação contínua da luta, a qual, talvez, somente seja possível por ser também pautada pela racionalidade ecológica, provocando $\mathrm{o}$ acirramento de velhas e a produção de novas contradições ao confrontar-se com a hegemonia da racionalidade econômica. Por fim, a agroecologia é compreendida na interação dos camponeses com pesquisadores, entidades e grupos sociais, o que, por sua vez, traz o desafio do diálogo em meio à pluralidade epistemológica.
\end{abstract}

Palavras chaves: agroecologia, racionalidade ecológica, campesinato

Resumen: A diferencia de las proposiciones de la "agricultura alternativa", cuyos deseos están limitados a idealizar a la reproducción del capital se puede producir sin causar efectos devassaladores, ambiental o social, en la perspectiva de la agroecología considerado por Altieri (2002), Guzmán; MOLINA (2005) y GUTERRES (2006) ya que el posicionamiento político e ideológico se requiere. En este caso, se inicia con la crítica de las bases estructurales del sistema de producción, y entiende la experiencia cotidiana del los campesinos como una continua renovación de la lucha que, tal vez, sólo es posible por ser también guiada por la racionalidad ecológica, que causa la intensificación de viejas contradicciones, y la producción de otras nuevas, mientras que trata de la hegemonía de la racionalidad económica. Por último, la agro-ecología se entiende en la interacción de los agricultores con investigadores, organizaciones y grupos sociales, que, a su vez, hace que el desafío del diálogo dentro de la pluralidad epistemológica.

Palabras clave: agroecologia, racionalidad ecológica, campesinos

\footnotetext{
${ }^{1}$ Graduada pelo Departamento de Geografia da Faculdade de Filosofia, Letras e Ciências Humanas da Universidade de São Paulo
} 
Abstract: Unlike those propositions of "alternative agriculture", whose longing are limited to idealize that reproduction of capital can occur without causing devastating effects, environmental or social, from the perspective of agroecology regarded by ALTIERI (2002), GUZMÁN; MOLINA (2005) and GUTERRES (2006) it's given that political and ideological positioning is required. In this case, from the critical of structural bases of the production system, peasant's everyday experience it's understood as a continuous renewal of the fight, which perhaps is only possible by be also guided by the ecological rationality, causing the intensification of old contradictions, and the production of new ones, through the confront with the hegemony of economic rationality. Finally, agro-ecology is understood in the interaction of farmers with researchers, organizations and social groups, which, in turn, brings the challenge of dialogue within the epistemological plurality.

Keywords: agroecological, ecological rationality, peasantry

\section{Agriculturas alternativas: Proposições eCologiCAMENTE CORRETAS}

No sentido de reduzir o impacto da produção agropecuária convencional, ou mesmo de estudar novas formas de organização dos agroecossistemas, ocorreram ao longo do século XX algumas proposições que acabaram sendo generalizadas e rotuladas como "agriculturas alternativas", ignorando suas especificidades teóricas, metodológicas e epistemológicas.

De forma geral, todos eles partem das consequiências da crise ecológica resultante da artificialização e simplificação da agricultura e de seus processos, oriundos da introdução da lógica da produção industrial na agricultura. Por outro lado, esses mesmos autores apoiados em pressupostos semelhantes, norteiam-se por diferentes construções teóricas e apresentam focos teóricos, metodológicos e inclusive epistemológicos diferentes. (IAMAMOTO, 2005:30)

A Figura 1 apresenta, sucintamente, as experiências que se opuseram à agricultura convencional e acabaram sendo estruturadas e divulgadas por pesquisadoresexperimentadores de diversos continentes, principalmente da Europa.

No entanto, as agriculturas indicadas, quando praticadas sob a lógica capitalista de produção no campo, muitas vezes acabam tendo sua capacidade de contestação limitada à reprodução de valores e atitudes que contribuem principalmente à continuidade do padrão vigente. CAPORAL e COSTABEBER (2004a: 60) citam como indicativos de tal reprodução: a substituição dos insumos, por outros de empresas 
controladoras do mercado de insumos orgânicos importados, a adequação às normas e regras das certificadoras internacionais para que os produtos possam ter os selos reconhecidos pelos consumidores deste nicho, a manutenção da monocultura, e a busca pelas melhores áreas; sendo todas as práticas definidas pelo mercado e que levam à intensificação contínua de capital. 
Figura 1 - Identificação das agriculturas alternativas

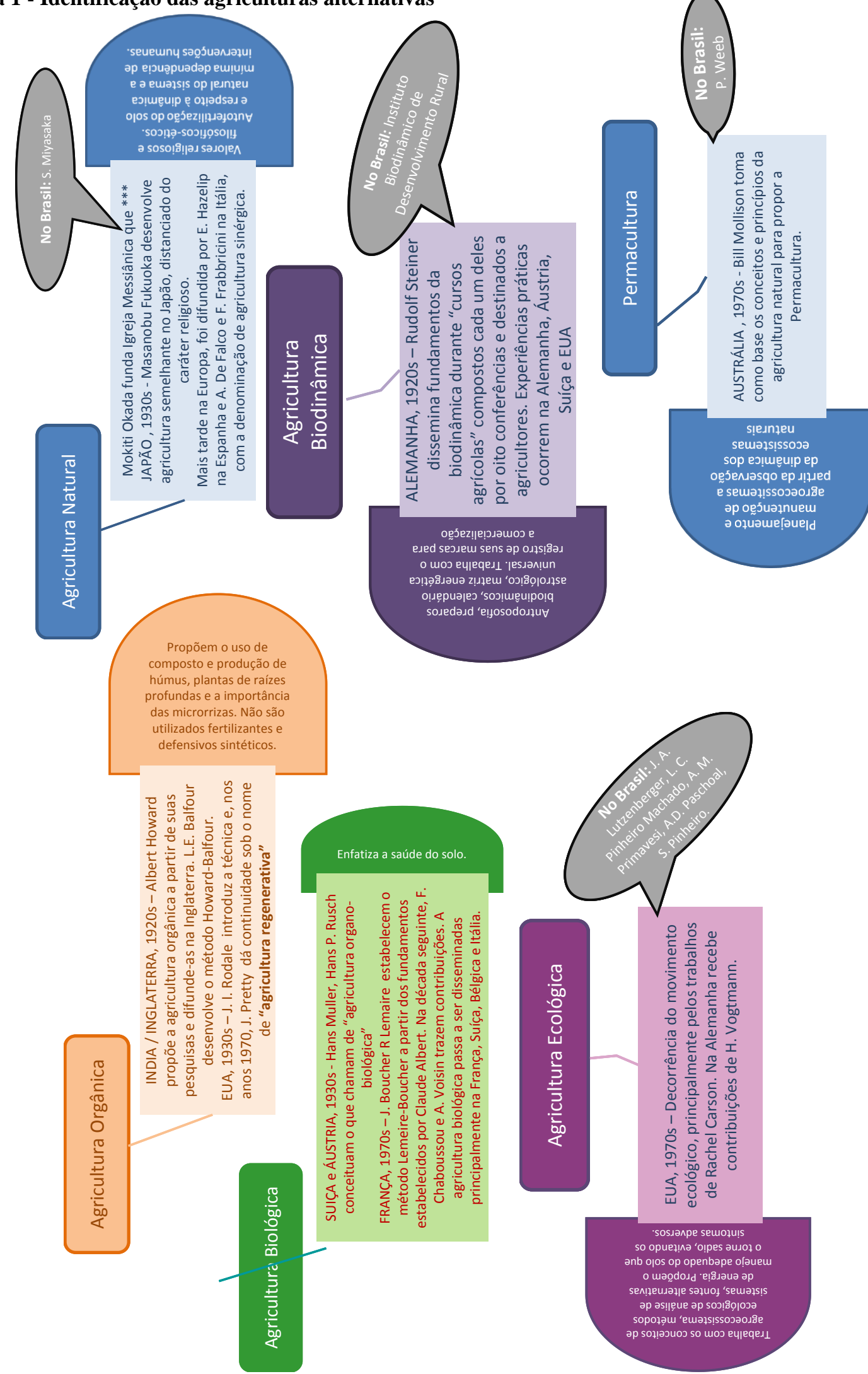

Fonte: GLIESSMAN, 2000; MARCOS, 2005. Elaboração: Paula Camargo 
Ou seja, os agricultores que praticam desta forma alguma das correntes da agricultura alternativa, tornam-se da mesma forma subordinados e dependentes em relação às grandes corporações transnacionais ${ }^{2}$, comprometendo a autonomia financeira e cultural dos mesmos. (CAPORAL; COSTABEBER, 2004b).

Outro aspecto, que levanta críticas à forma como as agriculturas alternativas foram pensadas e postas em prática, e ainda têm sido, refere-se à maneira fragmentada e parcial com que os aspectos ambientais são contemplados na produção. Por exemplo, a realização de uma única intervenção, como a troca de insumos químicos por orgânicos, pode vir a significar que todo o processo produtivo seja denominado ecológico e, assim, seus produtos rotulados como ecologicamente corretos para a devida aquisição por parte do respectivo segmento consumidor. Na realidade, ainda sem provocar contaminações pelo uso de insumos químicos, tal agroecossistema poderia estar sendo mantido à custa de exploração do trabalho, por solos empobrecidos e monocultivo.

Para CAPORAL e COSTABEBER (2004b: 08) se tratam de "vã tentativa de recauchutagem do modelo da Revolução Verde, sem qualquer propósito ou intenção de alterar fundamentalmente as frágeis bases que até agora lhe deram sustentação".

Tal inserção na lógica do "capitalismo verde" é realizada não somente por capitalistas que enxergam unicamente o lucro no recente público consumidor, mas também por aqueles que desejam vincular maiores ganhos monetários a práticas agropecuárias consideradas, por eles mesmos, menos danosas.

Há outros, porém, que consideram como necessária a adequação da produção ao mercado vigente, mas colocam que isso não deveria ser visto como o ponto de chegada e, sim, como meio de sobrevivência enquanto a utopia de uma nova produção e sociedade não possa ser vivenciada.

\footnotetext{
${ }^{2}$ Utilizam-se de insumos importados produzidos por corporações internacionais e aderiram às normas de certificadoras internacionais.

${ }^{3} \mathrm{O}$ capitalismo verde seria a apropriação do alarde ambiental promulgado por pesquisadores e políticos ainda em meados do século XX para que a solução fosse a adaptação do modo de produção capitalista, mantendo a racionalidade econômica, porém com uma maquiada preocupação ambiental.
} 
Diferenciando-se das chamadas agriculturas alternativas, a agroecologia é compreendida através de aspectos diferentes dos padrões vigentes. Assim, sua perspectiva considera o policultivo, o manejo em áreas menos aptas, a maior intensificação possível do trabalho e a menor de capital. A principal característica da agroecologia seja, talvez, que as orientações e decisões são dadas a partir da cultura e do agroecossistema local, mesmo quando imersa no sistema capitalista de produção e pressionada pelo mercado capitalista.

Ao tratar da agroecologia, portanto, a crítica extrapola questões tecnológicoculturais da revolução verde, alcançando questionamentos que indiretamente ou diretamente tratam da apropriação e concentração privada da terra, da água, dos recursos da floresta, do conhecimento etc.

O estado do Paraná, por exemplo, é um dos estados brasileiros que mais comercializa produtos sob rótulos de ecologicamente corretos inseridos na lógica do capitalismo verde, porém também se destaca por historicamente ser berço de entidades que trabalham no sentido de analisar criticamente as bases sustentadoras do modo de produção capitalista.

Reconhecemos a importância destes sujeitos sociais que se organizaram para lutar por transformações na agricultura e na sociedade e certamente contribuíram para transformações significativas na geografia da paisagem, tornando-a certamente mais heterogênea em termos de espécies animais e vegetais.

Tal processo contou com o envolvimento de articulações sociais de abrangência nacional, como a Comissão Pastoral da Terra (CPT), mas também de outras com atuação regionalizada, como é o caso das organizações não governamentais atuantes no Paraná, tais como: Fundação Rureco, Associação de Estudos, Orientação e Assistência Rural (Assessoar), Centro de Apoio ao Pequeno Agricultor (CAPA), Assessoria e Serviços a Projetos em Agricultura Alternativa (AS-PTA), Instituto Agro-florestal 
Bernardo Hakvoort (IAF) e o Instituto EQUIPE de Educadores Populares (IEEP). Outros sujeitos que contribuíram com novos olhares e estratégias de luta e organização no Paraná para a permanência ou retorno à terra são: Federação dos Trabalhadores na Agricultura Familiar da Região Sul (FETRAF-SUL/CUT), o Movimento dos Trabalhadores Sem Terra (MST) ${ }^{4}$, Movimento dos Pequenos Agricultores (MPA) e a Comissão Regional dos Atingidos por Barragens (CRAB). Há, ainda, as redes Associação para o Desenvolvimento da Agroecologia (AOPA) e a REDE ECOVIDA.

São diversas as motivações que levaram os movimentos e agricultores a se interessarem por técnicas e práticas diferenciadas e em negação àquelas adotadas na "Revolução Verde".

Poderíamos nos ater ao âmbito cultural, no sentido de uma "cultura camponesa" de dar prosseguimento aos aprendizados passados de pai para filho, continuando os tratos da terra e com os animais.

Porém, consideramos importante discutir os aspectos do âmbito econômico que podem ter sido decisivos no processo de aceitação, recusa e/ou adaptação da agricultura moderna, num primeiro momento. E de readaptação ou recusa às agriculturas chamadas "alternativas", num segundo momento.

Se por um lado havia a promessa do aumento da receita e da produtividade por parte da agricultura moderna, por outro, era necessário alto investimento monetário para que os novos pacotes tecnológicos pudessem ser adquiridos ${ }^{5}$. MAYER (2006), analisando a situação dos agricultores da região metropolitana de Curitiba (Paraná), faz referências a casos em que os produtores não conseguiram empréstimos via banco ou cooperativas de crédito e foram, de algum modo, segregados da chamada modernização da agricultura:

\footnotetext{
${ }^{4}$ O MST, principalmente a partir da virada do século, tem reconhecido a necessidade de reduzir progressivamente as relações de depenência que pautam a inserção dos assentamentos no mercado capitalista, passando a difundir a concepção de uma "nova matriz tecnológica" caracterizada por princípios agroecológicos.

${ }^{5}$ Desde sementes melhoradas, passando por insumos e defensivos, até novas ferramentas e novos maquinários.
} 
Embora não tenha incorporado integralmente os padrões produtivos da "Revolução Verde", a agricultura familiar da região, em sua grande maioria, adota manejos tradicionais que, no atual contexto, têm levado ao esgotamento da fertilidade natural dos solos e à degradação das fontes de água. Seus produtos são mal-remunerados e chegam aos mercados por meio de uma cadeia de intermediação que se apropria de parte significativa da renda gerada.

Diante desse panorama estrutural adverso, um número crescente de grupos e organizações da agricultura familiar se mobiliza para construir e disseminar alternativas técnicas, econômicas e sócioorganizativas para o enfrentamento das dificuldades. Assessorados pela Associação para o Desenvolvimento da Agroecologia (Aopa), esses grupos vêm promovendo ações em diferentes campos que, juntas, contribuem para a promoção de níveis superiores de sustentabilidade nos agroecossistemas geridos pela agricultura familiar da região. (MAYER, 2006:15-16)

Outros tantos podem ter tido recurso para investir, mas que não obtiveram o retorno financeiro esperado, obrigando-os a, no mínimo, renegociar as dívidas previamente realizadas com as agências financiadoras, públicas ou privadas.

A considerar a não acessibilidade da modernização da agricultura a grande parcela dos agricultores, tem-se que a continuidade ou retomada da produção agrícola de menor escala e sem uso de insumos ou defensivos químicos tornou-se uma falta de opção ou mesmo uma nova oportunidade de inserção no mercado. Aos poucos, uns por opção e outros por ser a única forma de continuar a produzir, passaram a apropriar-se do discurso dos "alimentos orgânicos", o qual começava a se constituir um nicho de mercado cada vez mais promissor.

Este nicho é sustentado pelas classes média e alta que, preocupadas com a sua dieta alimentar, diferenciam produtos orgânicos dos demais, considerados não ecologicamente corretos, e cujo poder aquisitivo propicia-lhes arcar com o diferencial de preço representado por tais alimentos e seus derivados.

É, portanto, nesse sentido que a adoção de práticas alternativas de manejo por si só não significa existir um posicionamento de contraposição à lógica de produção 
industrial no campo, assim como é considerado na agroecologia, conforme será tratado adiante.

WALDMAN (1992: 28) utiliza-se do termo "microempresa ecológica" para questionar a validade do "ecologismo elitista", que se aproveita do alarde da "crise ambiental" para desenvolver e vender produtos ecologicamente corretos.

Em meio à diversidade de interesses e posicionamentos, dentre a parcela de agricultores (proprietários, arrendatários ou meeiros) que deu continuidade ou retomou formas alternativas de manejo, destacamos aqueles camponeses que no dia a dia reafirmam a agricultura camponesa sob diferenciadas formas no lidar com a terra em seus respectivos agroecossistemas.

\begin{abstract}
Entendemos o campesinato como uma classe social e não apenas como um setor da economia, uma forma de organização da produção ou um modo de vida simplesmente. Enquanto o campo brasileiro tiver a marca da extrema desigualdade social e a figura do latifúndio se mantiver no centro do poder político e econômico - esteja ele associado ou não ao capital industrial e financeiro -, o campesinato permanece como conceito-chave para decifrar os processos sociais que ocorrem neste espaço e suas contradições. Portanto, defendemos a atualidade deste conceito, cuja densidade histórica nos remete a um passado de lutas no campo e ao futuro como possibilidade. (MARQUES, 2002:01)
\end{abstract}

\title{
2. O CAMPESINATO E A RACIONALIDADE ECOLÓGICA
}

A agricultura camponesa se organiza e se reinventa também com base na racionalidade ecológica. Esse era, inclusive, o alicerce de sua constituição até poucas décadas atrás, diferenciando-se das formas de manejo e organização que têm na racionalidade econômica seu eixo principal e que no campo têm na agricultura capitalista sua forma de manifestação. 
$\mathrm{Na}$ agricultura camponesa a relação com o seu meio se dá de forma a pensar na sua reprodução, nas necessidades da família, altamente dependente dos recursos naturais locais.

Para eles próprios e, consciente ou inconscientemente, a toda humanidade, os camponeses realizam múltiplos serviços no espaço rural, contribuindo para a diversificação da paisagem, das espécies, da alimentação, bem como para a manutenção e recuperação das águas, dos solos e do ar. (LEROY, 2002)

Os camponeses, dotados do acúmulo de saberes familiares, observam o espaço rural para que tais aprendizados possam ser cotidianamente incorporados à sua dinâmica, adaptando seus sistemas agrícolas de modo a produzir espaços diversificados e articulados entre si, certamente não delimitados pelas cercas físicas. "Os sistemas agrícolas são produtos da atividade humana e os fatores determinantes da agricultura não se limitam às cercas das propriedades rurais”. (ALTIERI, 2002:30)

Contudo, a intensificação das modificações socioeconômicas e territoriais tornou as famílias camponesas cada vez mais susceptíveis e dependentes das externalidades de seus sistemas agrícola, diferentemente de seus antepassados os quais vivenciaram momentos em que a dependência e subordinação de seu trabalho ao capital atingiam-nos mais lentamente, haja vista as diferentes realidades demográficas e tecnológicas.

Sejam camponeses agrícolas, pastoris, pesqueiros ou florestais, sejam proprietários, posseiros ou arrendatários de terra, suas lógicas de relações de produção e modo de vida diferenciam-se da lógica capitalista de produção; mesmo que todas as lógicas de produção estejam interligadas, dado que a existência de diversas formas de subordinação do trabalho ao capital é necessária à reprodução contínua e ampliada da lógica capitalista de produção. Assim, a existência da agricultura camponesa e dos processos que têm levado à sua reprodução, ao mesmo tempo em que produz contradições, é contraditória em si por ser estrutural do sistema. 
A existência e recriação de formas de produção não capitalistas são parte do processo histórico e dialético do modo de produção capitalista. Porém isto não significa que tais relações não capitalistas sejam aceitas e reconhecidas como legítimas. São evidentes e numerosos os exemplos de expropriação e exploração aos quais essas populações têm sido submetidas, e cuja principal característica de tais processos e ocorrências é a violência a qualquer tipo de resistência e luta. São também diferentes formas de violência que juntas acabam por impossibilitar a reprodução de modos de vida pautados por outras racionalidades.

É no reconhecimento da importância social das populações que lutam pela vida na área rural, que movimentos como a Via Campesina ${ }^{6}$ reúnem sob a denominação de "campesinato" tão variadas formas de viver e produzir.

\begin{abstract}
Essa diversidade camponesa inclui desde os camponeses proprietários privados de terras aos posseiros de terras públicas e privadas; desde os camponeses que usufruem dos recursos naturais como os povos das florestas, os agroextrativistas, a recursagem, os ribeirinhos, os pescadores artesanais lavradores, os catadores de caranguejos e lavradores, os castanheiros, as quebradeiras de coco babaçu, os açaizeiros, os que usufruem dos fundos de pasto até os arrendatários não capitalistas, os parceiros, os foreiros e os que usufruem da terra por cesão; desde camponeses quilombolas a parcelas dos povos indígenas já resultantes dos assentamentos de reforma agrária. (Via Campesina do $\mathrm{Brasil}^{7}$ (2004), apud GUTERRES, 2006: 70)
\end{abstract}

Ou seja, trata-se da constituição de um conceito para o reconhecimento e fortalecimento das populações rurais em respeito a sua singularidade, que justamente se opõe a qualquer forma de síntese, e se enriquece ao serem preservadas as denominações que cada indivíduo tem por si. Portanto, o conceito de camponês não deve ser confundido como um conceito-síntese normalmente utilizado nas políticas públicas no intuito de simplificar e igualar características e demandas, como fazem os conceitos de "pequeno produtor rural" ou "agricultor familiar", este último em uso atualmente. Traz ainda o significado de reconhecimento destas populações como agentes potenciais de

\footnotetext{
${ }^{6}$ A Via Campesina promove a luta internacional a favor da agricultura camponesa, em oposição à agricultura capitalista. Em 1995 o MST passou a integrar este movimento.

7 Via Campesina do Brasil. Estratégias para o desenvolvimento do campesinato no Brasil. (texto para debate). Brasília, mimeo, 37 páginas.
} 
transformação, passíveis de agregar força à luta inserida em contextos econômicos sob o sistema capitalista de produção.

No esforço de compreender quem seriam os sujeitos "camponeses", e verificar sua provável associação com princípios da agroecologia, identificam-se abaixo seus principais aspectos ${ }^{8}$ :

- A terra, o trabalho e a família como os valores morais e categorias nucleantes, bem como a honra, a hierarquia e a reciprocidade são seus princípios organizatórios.

- Preocupação com o auto-consumo e segurança alimentar da família segundo suas necessidades e desejos, prevalece o valor de uso sobre o valor de troca;

- A fim de prover segurança alimentar à família, promove a diversificação da produção através do uso diferenciado das terras, aproveitando suas especificidades físico-biológicas, em atenção ao relevo, solo, disponibilidade hídrica e florestal, entre outros. A construção de mosaicos produtivos tende a respeitar e beneficiar-se das características e potencialidades dos agroecossistemas locais. Assim, promove-se e incrementa-se a biodiversidade, também diversidade genética, contribuindo para maior estabilidade energética, visto que permite a redução da ação de pragas e doenças;

○ Organização do espaço rural também tendo como premissa a importância de promover a interação das atividades produtivas, num modelo em que o resíduo ou produto é insumo para outra atividade, refletindo na redução contínua de dependência de insumos externos e dos riscos;

- O estabelecimento de relações de vizinhança e reciprocidade entre famílias produtoras que passam a trocar seus recursos produtos, de origem animal ou vegetal, o que inclui também maquinários e a própria força de trabalho. Ainda que não mensurados monetariamente, tal dinâmica impacta positivamente a contabilidade da produção familiar;

\footnotetext{
8 Aspectos extraídos de diversos trabalhos, tal qual o de MARQUES (2002) que faz referência à WOORTMANN, Kaas (1990:11-73).
} 
○ Compreensão de co-evolução homem/natureza, quando a organização do espaço rural compreende o uso potencial e de longo prazo das espécies e dos recursos, inclusive aquelas desconhecidas, e não visa promover exclusivamente o manejo daquilo que possa resultar em ganho econômico imediato;

- O contato direto e intenso com o agroecossistema limita que sua produção ocorra normalmente em pequena e média escala o que viabiliza a compreensão das relações sistêmica naquela localidade. Por outro lado, os limites da propriedade nem sempre coincidem com a área de usufruto dos recursos naturais, compartilhando espaços de coleta, extração, pesca, plantio e criação animal, detendo a mesma importância;

- Ainda quando subordinados aos complexos agroindustriais, por exemplo, os camponeses detêm autonomia para tomadas de decisões, orientadas também pela racionalidade ecológica, o que os leva a compreender seu agroecossistema como lócus de reprodução da vida e repleta de significados e cosmologia;

- Sob a racionalidade ecológica, os camponeses apresentam formas diferenciadas de sociabilidades, bem como das relações homem/natureza.

Esses modelos e visões de mundo se colocam, muitas vezes, como instrumentos de resistência ante o avanço das práticas e dos modelos capitalistas. Auto-suficiência, autonomia, valor de uso, pequena escala, pouca disponibilidade de capital, redução de risco, conhecimento integrado/não fragmentado, trabalho e gestão familiar e potencialização dos recursos internos/locais são características, valores e estratégias camponesas que se manifestam diferenciadamente nos países de composição e miscigenação étnica diversas das puramente européias-ocidentais (TOLEDO, 1996). Esses conhecimentos e modelos são desconectados, em geral, da lógica moderna capitalista e construídos em processos históricos, às vezes bastante longos, frutos da co-evolução do sistema social com o sistema natural (NOORGARD; SIKOR, 2002). [...] São outros sistemas cognitivos, outras matrizes de racionalidade (PORTO GONÇALVES, 2001), outros gêneros de vida. (MAZZETO, 2004:349) 


\section{A PRODUÇÃO ACADÊMICA E AGROECOLOGIA}

Reflexões sobre os elementos que compõem a caracterização do camponês, diretamente associada à agroecologia, podem ser identificados hoje tanto na bibliografia da área de ciências humanas, quanto na área das ciências biológicas. Até 1980, no entanto, os referenciais sobre modo de vida e a abordagem da produção e organização espacial no meio rural não eram comuns às ciências biológicas.

Desde então os estudos voltados à ecologia agrícola, geralmente conduzidos pela Agronomia ou Ecologia, têm ao menos reconhecido a importância dos aspectos socioeconômicos, sejam eles internos ou externos aos agroecossistemas estudados, aproximando-se de conteúdos antes restritos às ciências humanas. Por vezes, parte destes estudos tem feito referência à terminologia "agroecologia".

O histórico da agroecologia na academia remete à década de 1920, quando a ecologia agrícola foi a responsável por estreitar os laços entre as áreas de Agronomia e Ecologia. Através da Teoria de Sistemas ${ }^{9}$, buscou-se prioritariamente a publicação de pesquisas com perspectiva à estabilização ecossistêmica, focada exclusivamente nos processos ecológicos. A qualidade e produtividade agrícola a longo prazo pautavam os estudos e o termo "agroecologia" começou, então, a ser utilizado.

Contudo, no final da década de 1930, o início da Segunda Guerra Mundial marcou o fortalecimento da agronomia e seus estudos experimentais voltados à produtividade no curto prazo, num processo de negação e desestruturação das pesquisas voltadas à ecologia agrícola.

Passaram décadas, para que somente a partir de 1970, a ecologia agrícola voltasse a ganhar importância no meio científico e em meio às discussões sobre

\footnotetext{
${ }^{9} \mathrm{O}$ uso da Teoria de Sistemas para os estudos da agroecologia faz sentido para este momento histórico, porém a crescente consideração de aspectos sociais, conforme será apresentado a seguir, deveria levar a reconsiderações sobre suas bases teóricas.
} 
ecossistemas e segurança alimentar. O agroecossistema manteve-se como unidade fundamental de análise, estando os outros fatores sociais e econômicos subordinados, em última instância, à elaboração e ao detalhamento ecológico de sistemas produtivos sustentáveis.

IAMAMOTO (2005:49) faz referência a diversos pesquisadores que, ainda na década de 1970, estudaram e sistematizaram de forma pioneira os sistemas camponeses no México, Espanha e Estados Unidos ${ }^{10}$, justamente por influência do movimento de contestação aos processos de modernização da agricultura.

Os estudos dos sistemas camponeses são considerados de grande importância para dali adiante os aspectos socioeconômicos passarem a compor as pesquisas da agroecologia.

Neste sentido ALTIERI (2002:44) e IAMAMOTO (2005:45) fazem menção a uma dezena de autores cujos trabalhos publicados na década de 1980 sobre agroecologia receberam ênfase das relações de produção. ${ }^{11}$

É também a partir de1970-80 que a agroecologia passa a receber definições teórico-metodológicas. A publicação em 1983 da primeira edição do livro "Agroecologia: as bases científicas da agricultura alternativa", de Miguel Altieri, repercutiu positivamente para a divulgação da agroecologia nas Américas. ${ }^{12}$

Os enfoques que percebem o problema da sustentabilidade somente como um desafio tecnológico da produção não conseguem chegar às razões fundamentais da não-sustentabilidade dos sistemas agrícolas. Novos agroecossistemas sustentáveis não podem ser implementados sem uma mudança nos determinantes socioeconômicos que governam

10 Os pesquisadores mencionados por IAMAMOTO (2005) são: Angel Palerm, Efraín Hernandez Xolocotzi, idéias desenvolvidas por Victo M. Toledo (mexicanos), Gliessman (americano), Joan Martinez Alier e José Manuel Naredo (espanhois).

${ }^{11}$ ALTIERI (2002:44) faz referência aos pesquisadores Richards (1985), Bremen e de Wit (1983), Watts (1983), Posey (1984), Denevan et. al. (1984), Brokenshaw et al. (1979) e Conklin (1956). Outros trabalhos com abordagem da agricultura e desenvolvimento regional: Altieri e Anderson (1986), Brush (1977), Richards (1984 e1986), Kurin (1983), Bartlett (1984), Hecht (1985) e Blaikie (1984).

${ }^{12}$ A edição em português foi publicada em 1989. 
o que é produzido, como é produzido e para quem é produzido. (ALTIERI, 2004: 16)

Em comum, consideram fundamentais que tanto os estudos quanto as práticas agrícolas tenham um trato qualitativo focado nas especificidades ecológicas, econômicas e culturais de cada propriedade, utilizando-se escala de análise apropriada.

\begin{abstract}
A idéia básica é a de que a agroecologia não pode ser implementada a partir de pacotes tecnológicos, requerendo, ao contrário, um tratamento qualitativo específico no contexto de cada propriedade (com base, por certo, em alguns princípios gerais). Esse tratamento, em seu sentido mais profundo, só pode ser realizado em escala apropriada, descentralizada, e mediante a gestão da terra e dos recursos dirigida por indivíduos para quem a propriedade não seja apenas uma fonte objetiva de lucros, mas, sim uma fonte de vida e de conhecimentos. (...) A agroecologia, ao envolver um certo caráter artesanal, associa-se bem melhor à escala da gestão familiar. (BRACAGIOLI, 2003: 46)
\end{abstract}

Nos enfoques recentes, a agroecologia é compreendida pela interação das ciências biológicas e humanas com os conhecimentos tradicionais camponeses. O desafio comum a todos eles, segundo PERTESEN (2002), é superar os obstáculos epistemológicos existentes entre agricultores, pesquisadores, militantes - e interno a cada um deles - ao promover o "encontro do mundo dos agricultores-experimentadores (forma de conhecimento não linear, intuitiva e integradora) e dos pesquisadores acadêmicos (forma de conhecimento linear, racional e analítico)". (PERTESEN: 2007)

Para além das diferenças quanto ao conteúdo, a centralidade da questão talvez seja justamente a maneira pela qual o campesinato organiza e compartilha suas experiências e seus aprendizados. Ou seja, qualquer interação requer pluralidade epistemológica. "Trata-se, na verdade, de um sistema de organização econômica cuja apreensão analítica demanda a formulação de uma estrutura conceitual e metodológica ajustada e inteiramente nova." (GOMES DE ALMEIDA, 2005:05)

Estudiosos como CAPORAL, COSTABEBER (2000) e GLIESMMAN (2000) enfatizam a importância da constituição da agroecologia como categoria científica voltada à dinamização daquilo que identificam como "agricultura familiar", 
semelhantemente às políticas públicas que enxergam o agricultor como pequeno empreendedor do desenvolvimento rural sustentável.

Numa outra vertente, ALTIERI (2002), GUZMÁN; MOLINA (2005) e GUTERRES (2006), por exemplo, não fazem referências à agroecologia como categoria científica, mas destacam a necessidade de situar o agroecossistema e os camponeses em contextos mais amplos e historicamente construídos, tal como a sociedade no estágio atual de desenvolvimento capitalista. Estabelecem diálogos com a antropologia, sociologia rural e economia, buscando compreender relações complexas de interação entre o que ALTIERI (2002) denomina "sistemas ecológicos" e "sistemas sociais" 13.

A agroecologia pode ser melhor descrita como uma abordagem que integra concepções e métodos de diversas outras áreas do conhecimento e não como uma disciplina específica. (...) Cada uma destas áreas apresenta diferentes objetivos e metodologias, ainda que tomadas em conjunto, todas têm influência legítima e importante no pensamento agroecológico. (ALTIERI, 2002:31)

Outra diferenciação está ao identificar, por exemplo, as relações sociais e o sistema de produção como peças chaves, tal como colocam GUZMÁN; MOLINA (2005) e ALTIERI (2002) e GUTERRES (2006), e não apenas complementares, para a compreensão e intervenção nos sistemas agrários, conforme CAPORAL; COSTABEBER (2000) e GLIESSMAN (2000).

Ainda, assim, ao tratar da agroecologia tanto ALTIERI (2002) quanto (GLIESSMAN, 2000) propõem o uso da expressão “sistema agro-alimentar", na medida permite a ampliação do enfoque para a "produção agrícola, distribuição de recursos, processamento e comercialização de produtos numa região e/ou num país." (ALTIERI, 2002:85)

À medida que reconhecemos a influência de fatores sociais, econômicos, culturais e políticos sobre a agricultura, devemos também mudar nosso enfoque, da sustentabilidade dos agroecossistemas para a

\footnotetext{
${ }^{13}$ Novamente o referencial utilizado é a Teoria de Sistemas, o que reflete a ausência de trabalhos desenvolvidos por pesquisadores das ciências humanas que tenham outras vertentes teóricas, que por sua vez poderiam problematizar e apontar eventuais limitações do empirismo lógico.
} 
sustentabilidade de nossos sistemas alimentares. (GLIESSMAN, 2000:600)

ALTIERI (2002), especificamente, parte da teoria geral dos sistemas para estabelecer as relações existentes de um sistema agrícola, organizado na relação entre sistemas internos e externos, sociais e ambientais. Faz a proposição de uma série de parâmetros e enquadramentos para a sistematização de análises socioeconômicas que se pretende realizar, parte destas compostas de informações qualitativas. Realiza, por exemplo, estudos comparativos, ressaltando contrastes decorrentes do tamanho da propriedade, da disponibilidade de capital frente a um mesmo tipo de sistema de produção agropecuário. Contudo, ele próprio reconhece que: "Existem, no entanto, poucos instrumentos ou indicadores adequados para avaliar a viabilidade, adaptabilidade e durabilidade dos programas agroecológicos.” (ALTIERI, 2004:50)

GUZMÁN; MOLINA (2005) por sua vez, identificam a agroecologia como uma orientação teórica que incide sobre diversos campos do conhecimento. Suas reflexões sobre o conceito de desenvolvimento rural retomam a questão agrária russa do século XIX, trazendo o debate entre os marxistas ortodoxos e populistas, ou Narodniki, sobre o papel do campesinato em meio ao desenvolvimento capitalista na Rússia e seu avanço sobre o campo.

Assim como GUZMÁN; MOLINA (2005), GERMER (2006) na perspectiva de análise marxista propõe a reflexão quanto ao rumo tecnológico da agricultura frente à viabilização dos assentamentos de reforma agrária, inseridos no contexto de luta de classes. Deixa claro a necessidade de organizar a luta para a redistribuição de toda a estrutura produtiva, e não somente da terra.

Por fim, Enio GUTERRES traz uma perspectiva utópica da agroecologia e considera que "essa utopia permite a produção de tensões necessárias ao enfrentamento da dependência." (GUTERRES: 2006,133). Destaca que a agroecologia, tendo como base o resgate dos saberes tradicionais, requer a retomada da consciência de classe no sentido de positivar a concepção de campesinato. 
Agroecologia é uma forma de entender a atuar para campenisar a agricultura, a pecuária, o florestamento e o agroextrativismo, a partir de uma consciência intergeneracional (não exploração de crianças e velhos), de classe (não exploração do capital ao trabalho), de espécie (não exploração dos recursos naturais), de gênero (não exploração do homem à mulher), de identidade (não exploração entre etnicidades). (GUTERRES, 2006:90)

Os autores acima destacados foram priorizados neste artigo por serem sensibilizados pelos impactos ambientais que assolam todo o mundo, mas por terem claro que a problemática principal não reside numa crise do modelo tecnológico, mas sim por enxergarem que por detrás estão "as relações sociais e forças econômicas que direcionam e legitimam o modo de produção em questão" (IAMAMOTO, 2005:49). Questões como 'reforma agrária' e 'segurança e soberania alimentar' compõem as bibliografias consultadas.

\section{Processos de transição}

Se o campesinato que temos feito referência não ficou imune às transformações socioterritoriais e ambientais promovidas pelo avanço do capitalismo no campo, é comum a existência de famílias produtoras que há décadas vêm realizando o manejo convencional de seu agroecossistema.

Não podemos esquecer que a terra está contaminada e depende de insumos químicos. Ao redor continuam as práticas da monocultura e do uso intensivo de venenos. O pequeno agricultor não é uma ilha. As práticas dos vizinhos afetam as suas. E muitos conhecimentos básicos de uma agricultura diversificada, ecológica e sem venenos foram esquecidos. E entre um prejuízo insuportável para o pequeno agricultor e o uso de alguma técnica ou insumo da "revolução verde", ele não tem alternativas a não ser continuar usando. (GUTERRES, 2006:18)

Assim, dada a intenção de realizar a transição do manejo convencional para o agroecológico, este processo tem que ser realizado de acordo com cada localidade, em 
consideração ao processo histórico sociocultural, sua organização social e territorial, o que depende das relações homem/natureza, seus valores e simbologias.

Contudo, a autonomia camponesa não deve ser compreendida somente em relação à dependência dos insumos externos e às políticas extensionistas de imposição e novos conhecimentos e técnicas. Há comunidades que realizam a pesca, agricultura e o extrativismo que não tiveram acesso ou interesse em promover a modernização de seus processos produtivos.

Experiências vêm demonstrando a importância do diálogo e da troca de aprendizados entorno de princípios agroecológicos a fim de inovar práticas tradicionais para suprir parte das demandas e necessidades atuais destas comunidades.

É preciso ir reforçando a partir de práticas concretas os elementos que diminuem a dependência e aumentam a autonomia do camponês na construção de um novo jeito de produzir na terra. (GUTERRES, 2006: 18)

A experiência relatada por MARCIEL et al (2006) na região de Cametá, estado do Pará, a qual tem no extrativismo do açaí sua principal atividade, é um exemplo dos manejos que não foram objeto direto da modernização da agricultura. No entanto, dado o contexto socioeconômico sentem indiretamente os efeitos pela redução da qualidade das águas, disponibilidade de animais marinhos, e por dificuldades de acesso ao mercado consumidor o qual traz exigências técnicas, sanitaristas e organizativas cada vez maiores.

Na perspectiva da transição para a agroecologia, ONGs com atuação em todo o território nacional têm promovido formação e extensão rural a partir de metodologias de "investigação-ação participante" ou "agricultor-experimentador", em que "A ciência entra como um processo de retroalimentação entre teoria e prática" (PETERSEN et al, 2002:18) 
No estado do Paraná é marcante a atuação AS-PTA cuja metodologia de investigação-ação participante parte da "revalorização dos conhecimentos tradicionais a respeito do manejo agrícola" (PETERSEN et al, 2002:18) para problematizar os agroecossistemas camponeses, para então via "amplo processo de experimentação e intercâmbio de inovações técnicas e sociais" desenvolverem e implementarem juntos as novas proposições.

Ademais, vale ressaltar que no Rio Grande do Sul (RS), ainda no início da década de 1980, as mobilizações civis no sentido de reduzir as queimadas, os desmatamentos e o uso de defensivos agrícolas foram aos poucos sendo introduzidas nas políticas públicas do estado, principalmente no que diz respeito a reestruturar a então vigente política de extensão rural via a Empresa de Assistência Técnica Rural do Rio Grande do Sul (EMATER), a qual havia sido implementada em 1955 em meio às políticas de modernização da agricultura.

Aos poucos, a realização de atividades de capacitação, relacionamento mais próximo do produtor e uso de novas metodologias de trabalho fez com que a extensão rural no estado do Rio Grande do Sul (RS) recebesse nova adjetivação, a “agroecológica". Segundo CAPORAL; COSTABEBER (2004a), a Extensão Rural Agroecológica apresenta metodologias de "investigação-ação participante":

[...] que permitam o desenvolvimento de uma prática social mediante a qual os sujeitos do processo buscam a construção e sistematização de conhecimentos que os levem a incidir conscientemente sobre a realidade, com o objeto de alcançar um modelo de desenvolvimento socialmente eqüitativo e ambientalmente sustentável, adotando os princípios teóricos da Agroecologia como critério para o desenvolvimento e seleção das soluções mais adequadas e compatíveis com as condições específicas de cada agroecossistema e do sistema cultural das pessoas implicadas em seu manejo. (CAPORAL; COSTABEBER, 2004a: 34)

Décadas depois, em 2004, a EMATER passou a contar com a Política Nacional de Assistência Técnica e Extensão Rural (PNATER), resultante de um longo processo de articulação com os movimentos sociais e sociedade civil organizada. 
Dentre seus princípios está o rompimento com o modelo extensionista baseado na difusão do conhecimento e nos pacotes da Revolução Verde e a adoção da agroecologia como paradigma tecnológico. Segundo o documento [PNATER], as atividades de assistência técnica e extensão rural devem partir da análise dos diferentes agroecossistemas, da diversidade cultural e condições socioeconômicas, devendo desempenhar o papel de facilitadores através de metodologias participativas." (BORGES, 2007:127-128)

Ainda que notadamente as proposições da EMATER-RS se destaquem, inclusive frente às demais unidades da EMATER dispersadas em território nacional, trata-se de um organismo púbico que vem representar os interesses do Estado.

O mesmo ocorre com a criação em 2003 da linha de crédito exclusivo à agroecologia, denominado Programa Nacional de Fortalecimento da Agricultura Familiar (PRONAF) Agroecologia, o qual compreende a "Linha para o financiamento de investimentos dos sistemas de produção agroecológicos ou orgânicos, incluindo-se os custos relativos à implantação e manutenção do empreendimento" (MINISTÉRIO DO DESENVOLVIMENTO AGRÁRIO, 2010). Dentre outros créditos que se diferenciam, porém reforçam a lógica do capitalismo verde, inclusive por criarem dependência financeira e possíveis endividamentos, estão: "PRONAF Eco", voltado a tecnologias para reduzir o impacto ambiental das atividades rurais, e o "PRONAF Floresta", cujo foco está nos sistemas agroflorestais e na preservação de áreas de proteção.

BORGES (2007) coloca que as exigências para a obtenção de crédito, especificamente quanto à linha PRONAF Agroecologia, destoam das realidades locais.

Apesar dessa inovação, as exigências governamentais obrigavam os agricultores a apresentar um planejamento de transição a curto prazo, o que não é compatível com os elementos de conversão agroecológica. Isso dificultou o acesso ao crédito por grande parte dos produtores, os quais não conseguiam atender as condições de financiamento. Diante desse quadro, essa modalidade de PRONAF apresenta-se inadequada à produção agroecológica no país, cujas práticas estão, em sua maioria, em processo de avaliação e aperfeiçoamento. (BORGES, 2007:128-129) 
As abordagens da EMATER-RS, do PRONAF, e mesmo a de alguns acadêmicos, consideram a agroecologia como referencial teórico supostamente neutro, a ser incorporado nas políticas de desenvolvimento rural sustentável, compatível ao e parte do modo de produção capitalista. Este também é o posicionamento dos eventos acadêmicos estaduais ou nacionais, como os congressos e seminários de Agroecologia, apoiados pelo Ministério do Desenvolvimento Agrário (MDA) do Governo Federal.

ALMEIDA (2002), por exemplo, faz críticas negativas à vinculação da agroecologia com "campo político-ideológico" através de "ideário político partidário ou com grupos políticos específicos”. Segundo o mesmo, o posicionamento políticoideológico acaba por fragilizar a mobilização em torno da agroecologia e sua constituição como um "movimento agroecológico".

No entanto, a diversidade existente é justamente reflexo de posicionamentos político-ideológico distintos, e que acabam por direcionar a escolha metodológica e o objeto das ações seja por agricultores, pesquisadores ou grupos organizados. Os eventos da Jornada Paranaense de Agroecologia e do Encontro Nacional de Agroecologia (ENA) reúnem desde pesquisadores e funcionários públicos, ONGs e movimentos sociais engajados na militância política por transformações sociais, estruturais ou não. Em ambos agroecologia pode ser compreendida de diferentes formas, menos neutra.

Neste sentido, a promoção da agroecologia de acordo com seus princípios tornase-ia viável sob outro sistema de produção. Nos processos de transição, transformação, ou melhor, ruptura das bases estruturantes, a classe social do campesinato é de fundamental importância por deter, ainda, acesso à terra e a outras formas de racionalidades. 


\section{REFERÊNCIAS BIBLIOGRÁFICAS}

ALMEIDA, Jalcione. Agroecologia: paradigma para tempos futuros ou resistência para o tempo presente? In.: Desenvolvimento e Meio Ambiente: Caminhos da agricultura ecológica. v.6, n.1, p. 29-40. Curitiba: Editora UFPR, 2002.

ALMEIDA, Sílvio Gomes de. Economia familiar: modo de produção e modo de vida. Revista Agriculturas: experiências em agroecologia. v.2, n.3, outubro. Rio de Janeiro, AS-PTA: 2005.

ALTIERE, Miguel. Agroecologia: bases científicas para uma agricultura sustentável. Guaíba: Agropecuária, 2002 Agroecologia: a dinâmica produtiva da agricultura sustentável. 4 ed. Porto Alegre: Editora da UFRGS, 2004.

BORGES, Juliano Luis. A transição do MST para a agroecologia. Dissertação (Ciências Sociais) Universidade Estadual de Londrina: Londrina, 2007.

BRACAGIOLI, Alberto. Desenvolvimento e envolvimento da agricultura no sul do Brasil: abordagem crítica do processo de desenvolvimento. Encontro Nacional de Agroecologia. Anais. Rio de Janeiro: AS-PTA, 2003. p. 33-35

CAPORAL, Francisco Roberto; COSTABEBER, José Antônio. Desenvolvimento rural sustentável: perspectivas para uma nova Extensão Rural. Agroecologia $e$ Desenvolvimento Rural Sustentável, v. 1, n.1, p. 16-37, jan./mar. 2000. - Agroecologia e Extensão Rural: Contribuições para a promoção do Desenvolvimento Rural Sustentável. Brasília: MDA/SAF/DATER, 2004a. Agroecologia: alguns conceitos e princípios. Brasília: MDA/SAF/DATERIICA, 2004b.

GERMER, Claus. Anotações críticas sobre o papel da C\&T na reforma agrária. In. CONCRAB. Reforma Agrária \& Meio Ambiente. Ano 1, n.1, p. 41-56, novembro. São Paulo, 2006.

GLIESSMAN, Stephen R. Agroecologia: processos ecológicos em agricultura sustentável. Porto Alegre: Ed. Universidade UFRGS, 2000. 
GREMPEL, Mary Beatriz. Os assentamentos rurais coletivos do noroeste do Paraná e a participação da mulher nos processos de luta. Dissertação (Mestrado em Geografia) Presidente Prudente: UNESP, 2001.

GUTERRES, Ivani. Agroecologia militante: contribuições de Enio Guterres. São Paulo: Expressão Popular, 2006.

GUZMÁN, Eduardo Sevilla; MOLINA, Manuel González de. Sobre a evolução do conceito de campesinato. 3. ed. São Paulo: Expressão Popular, 2005.

IAMAMOTO, André Toshio Villela. Agroecologia e Desenvolvimento Rural. Piracicaba, 2005. Dissertação de Mestrado em Recursos Florestais. Escola Superior de Agricultura Luiz de Queiroz, 2005.

LEROY, Jean-Pierre et al. Tudo ao mesmo tempo agora - desenvolvimento, sustentabilidade, democracia: o que isso tem a ver com você? Petrópolis:Vozes; Rio de Janeiro: FASE, 2002.

MARCIEL, Franquismar et al. Aprimorando o manejo tradicional de açaizais nativos. Revista Agriculturas: experiências em agroecologia. v. 3, n. 3, outubro. Rio de Janeiro, AS-PTA: 2006.

MARCOS, Valéria de. Construindo Alternativas: a produção agroecológica através da mandala. In. Anais do Simpósio Nacional de Geografia Agrária, III, Presidente Prudente, 2005. (informação pessoal)

MARQUES, Marta Inez Medeiros. A atualidade do uso do conceito de Camponês. In. Anais do Encontro Nacional de Geógrafos, XIII, João Pessoa, 2002.

MAYER, Paulo Henrique. Transição Agroecológica na Região de Curitiba. Revista Agriculturas: experiências em agroecologia. v. 3, n. 3, outubro. Rio de Janeiro, AS-PTA: 2006.

MINISTÉRIO DO DESENVOLVIMENTO AGRÁRIO. Linhas de creditos do Pronaf. Disponivel em: <http://portal.mda.gov.br/portal/saf/programas/pronaf/2258856>. Acesso em : 05 jan 2009 e 10 jan 2010.

PETERSEN, Paulo. Agricultura sustentável: um desafio político. Disponível em: http://www.agroecologia.org.br/modules/articles/article.php?id=30. Acesso em: 15 set 2007. 
Fundamentos da transição agroecológica: racionalidade ecológica e campesinato, 181 pp. 156-181

PETERSEN, Paulo; TARDIN, José Maria; MAROCHI, Francisco M. Tradição (agri) cultural e inovação agroecológica - facetas complementares do desenvolvimento agrícola socialmente sustentado na região centro-sul do Paraná. Rio de Janeiro: Gráfica Popular, 2002.

SILVA, Carlos Eduardo Mazzetto. Políticas Públicas e Desenvolvimento Rural: em busca de novos caminhos. In: OLIVEIRA, Ariovaldo Umbelino de; MEDEIROS, Marta Inez. (Org.). O Campo no Século XXI: território de vida, de luta e de construção da justiça social. p 335-352. São Paulo: Casa Amarela; Paz e Terra, 2004.

WALDMAN, Maurício. Ecologia e lutas sociais no Brasil. São Paulo: Contexto, 1992. 